\title{
Core-Shell Au-Ag Nanoparticles in Dielectric Nanocomposites with Plasmon-Enhanced Fluorescence: A New Paradigm in Antimony Glasses
}

\author{
Tirtha Som and Basudeb Karmakar $(\bowtie)$ \\ Glass Technology Laboratory, Glass Division, Central Glass and Ceramic Research Institute (Council of Scientific and Industrial \\ Research), 196, Raja S. C. Mullick Road, Kolkata 700 032, India \\ Received: 17 April 2009 / Revised: 19 May 2009 / Accepted: 20 May 2009 \\ (C)Tsinghua University Press and Springer-Verlag 2009. This article is published with open access at Springerlink.com
}

\begin{abstract}
The nano era demands the synthesis of new nanostructured materials, if possible by simplified techniques, with remarkable properties and versatile applications. Here, we demonstrate a new single-step reproducible melt-quench methodology to fabricate core-shell bimetallic $\left(\mathrm{Au}^{0}-\mathrm{Ag}^{0}\right)$ nanoparticles $(28-89 \mathrm{~nm})$ embedded glasses (dielectrics) by the use of a new reducing glass matrix, $\mathrm{K}_{2} \mathrm{O}-\mathrm{B}_{2} \mathrm{O}_{3}-\mathrm{Sb}_{2} \mathrm{O}_{3}$ (KBS) without applying any external reducing agent or multiple processing steps. The surface plasmon resonance (SPR) band of these nanocomposites embedded in KBS glass is tunable in the range 554-681 nm. More remarkably, taking advantage of the selective reduction capability of $\mathrm{Sb}_{2} \mathrm{O}_{3}$, this single-step methodology is used to fabricate inter-metallic: rare-earth ions co-embedded ( $\mathrm{Au}-\mathrm{Ag}: \mathrm{Sm}^{3+}$ ) dielectric (glass)-based-dnanocomposites and study the effect of enhanced local field on the red upconversion fluorescence of $\mathrm{Sm}^{3+}$ ions at $636 \mathrm{~nm}$. The enhancement is found to be about 2 folds. This single-step in-situ selective reduction approach can be used to fabricate a variety of hybrid-nanocomposite devices for laser based applications (see supplementary information).
\end{abstract}

\section{KEYWORDS}

Gold-silver nanostructures, core-shell morphology, surface plasmon resonance, antimony glass, metal-enhanced rare earth fluorescence

\section{Introduction}

A mandatory intermediary step involving the synthesis of metallic nanoparticles (NPs) and their exploitation in practical devices is their assembly within solid dielectrics, which in turn can be developed into novel devices [1, 2]. So, development of insulator glass doped matrices doped with metal or semiconductor nanocrystals is currently underway
[3-8]. Such metal-glass nanocomposites endow advanced functional properties which make them suitable for many applications like solid-state lasers, catalysis, sensors, dichroic polarizers and colored glasses, and as optoelectronic materials based on their nonlinear optical properties as well as single-electron tunneling and charging phenomena [8-11]. Glasses bestow some superior inherent properties like high transparency, mechanical strength, ease of fabrication

Address correspondence to basudebk@cgcri.res.in 
in desirable shapes and sizes and absence of metalligand interaction, which has often been discussed controversially, which make them promising hosts for encapsulating both metal nanocrystals and rare earth ions. Consequently, an emerging application of metal-glass nanocomposites in the field of plasmonics is their development as substrates (hosts) capable of providing large electromagnetic enhancements or "hot spots" formation for surfaceenhanced spectroscopies of rare-earth ions [1214]. Such enhanced local field properties originates due to surface plasmon resonance (SPR) in metallic nanostructures which is the collaborative oscillations of the free conduction band electrons on the metal surface on resonant excitation with electromagnetic radiation (light) $[15,16]$. The surface plasmon enhanced luminescence observed in monometallic: rare-earth (RE) hybrid composites have currently captured exponential attention due to their relevance as color displays, optical amplifiers as well as optical sensors [12-14].

The unusual optical and electrical properties of metal-glass nanocomposites arise due to several factors like modification of the electronic structure of metal NPs, interpley between volume and surface properties, chemical reactions between the nanocluster and the embedding matrix or interparticle interactions [17]. Bimetallic NPs, either as alloys or as core-shell structures, are more attractive over monometallic nanocrystals because they exhibit improved electronic, optical, and catalytic performances [18-20]. They have an additional degree of freedom, that is composition, which provides yet another dimension in tailoring the properties of bimetallic nanoparticles besides the usual size and shape manipulation. Thus, investigation of surface plasmon enhanced luminescence of RE ions by inter-metallic alloy NPs can set a paradigm in the burgeoning discipline of plasmonics.

However, fabrication of nano scale monometallic and particularly inter-metallic particles encapsulated within dielectric (glasses) matrices are not simple and encounter several difficulties like different chemical reactivities of two metals with the matrix, which can promote separation (via oxidation, for instance) instead of alloying of the species. Literature reports show several multi-stage approaches, such as solgel process, metal-dielectric co-sputtering deposition, metal-ion implantation, pulsed laser deposition, ion-exchange of thin plates followed by long time heat treatment at high temperatures in reducing atmosphere $\left(\mathrm{H}_{2}\right)$ or UV-light/X-ray/Co $\gamma$-radiation or laser/synchrotron irradiation, have so far been used to incorporate thin layers of metal nanoclusters within high phonon energy dielectrics, like silicate, borate, and phosphate glass matrices [3-8] while bimetallic-glass composites are relatively few. Therefore, simplification of preparation techniques and production of new bulk dielectric (glass) matrices incorporating metal nanoparticles with an extensive range of applications are of paramount importance.

Heavy metal oxide-based glass hosts with low phonon energy (resonance vibration of the matrix) are more favorable to diminish the multiphonon relaxation and increase the upconversion efficiency of RE ions [12, 13]. Among the heavy metal oxide glasses, $\mathrm{Sb}_{2} \mathrm{O}_{3}$-based systems have captured our attention for photonic, particularly surface-plasmonenhanced luminescence applications due to its two unique properties. Firstly, it possesses quite low phonon energy $\left(602 \mathrm{~cm}^{-1}\right)$ compared to conventional glass systems [21]. Secondly, it is a mild reducing agent $\left(\mathrm{Sb}^{5+} / \mathrm{Sb}^{3+}, E^{0}=0.649 \mathrm{~V}\right)$ [22] and its selective reduction property can be utilized to synthesize nano bimetal-embedded and bimetal:RE co-embedded (hybrid) nanocomposites. Here we have represented how these two properties of antimony glasses make them unique for photonic application in the entire glass family. It must also be emphasized that the area of nano metals-doped and RE-doped $\mathrm{Sb}_{2} \mathrm{O}_{3}$ (heavy metal oxide)-based glasses and nanocomposites have remained unexploited because of their difficulties in preparation particularly in the bulk monolithic form which is very much essential for practical application. Limited available reports on preparation of high $\mathrm{Sb}_{2} \mathrm{O}_{3}$ containing glasses show that they all yielded in very tiny pieces or pulverized form [2325]. The low field strength (0.73) of $\mathrm{Sb}^{3+}$ makes it a poor glass former [25]. Also, intense vaporization of $\mathrm{Sb}_{2} \mathrm{O}_{3}$ during melting and high devitrification during casting has made their synthesis very much difficult. Consequently, there is no report of metal-antimony 
glass nanocomposites.

In this study, by proper selection of composition, melting temperature, time, and casting mould, we demonstrate a new innovative simple single-step melt-quench technique to synthesize monolithic $\mathrm{Sb}_{2} \mathrm{O}_{3}$-based nano $\mathrm{Au}-\mathrm{Ag}$ alloy (having core-shell morphology)-embedded and alloy ( $\mathrm{Au}-\mathrm{Ag}): \mathrm{RE}\left(\mathrm{Sm}^{3+}\right)$ co-embedded hybrid nanocomposites and thereby exploit their optical and photonic properties.

\section{Experimental}

The raw materials were potassium metaborate, $\mathrm{KBO}_{2} \cdot x \mathrm{H}_{2} \mathrm{O}\left(15.7 \mathrm{wt} \% \mathrm{H}_{2} \mathrm{O}\right.$, Johnson Matthey), antimony (III) oxide, $\mathrm{Sb}_{2} \mathrm{O}_{3}$ (GR, 99\%, Loba Chemie), chloroauric acid, $\mathrm{HAuCl}_{4} \cdot x \mathrm{H}_{2} \mathrm{O}(49 \% \mathrm{Au}$, Loba Chemie), silver nitrate, $\mathrm{AgNO}_{3}$ (99.9\%, Exceller, Qualigens), and $\mathrm{Sm}_{2} \mathrm{O}_{3}$ (99.99 \%, Indian Rare Earth).

The base glass (A1) of the composition ( $\mathrm{mol} \%$ ) $15 \mathrm{~K}_{2} \mathrm{O}-15 \mathrm{~B}_{2} \mathrm{O}_{3}-70 \mathrm{Sb}_{2} \mathrm{O}_{3}$ was prepared by melting 20 $\mathrm{g}$ glass equivalent batch using above raw materials, that is, well mixed mixture of $17.85 \mathrm{~g} \mathrm{Sb}_{2} \mathrm{O}_{3}$ and 2.49 $\mathrm{g} \mathrm{KBO} \cdot x \mathrm{H}_{2} \mathrm{O}$, in a $25 \mathrm{~mL}$ high purity silica crucible at $900{ }^{\circ} \mathrm{C}$ in air for $10 \mathrm{~min}$ in a raising hearth electric furnace followed by one stirring of $0.5 \mathrm{~min}$ with a silica glass rod. All Au and/or Ag doped nanocomposites were prepared in a similar way by adding the required quantity (see Table 1) of $\mathrm{HAuCl}_{4} \cdot x \mathrm{H}_{2} \mathrm{O}$ and / or $\mathrm{AgNO}_{3}$ to the batch composition of the base glass (A1). It is to be noted here that all the concentrations of Ag and/or $\mathrm{Au}$ are in excess over the base glass (A1) composition. The $\mathrm{Au}-\mathrm{Ag}$ and $\mathrm{Sm}^{3+}$ codoped nanocomposites were also prepared in an analogous manner by adding the requisite quantity of $\mathrm{HAuCl}_{4} \cdot x \mathrm{H}_{2} \mathrm{O}, \mathrm{AgNO}_{3}$ and $\mathrm{Sm}_{2} \mathrm{O}_{3}$ (in excess) to the batch composition of the base glass (A1). All the glass melts were cast into a carbon plate and annealed at $260{ }^{\circ} \mathrm{C}$ for $3 \mathrm{~h}$ to reduce the internal stress and then very slowly cooled down to room temperature. Samples of about $2.0 \mathrm{~mm} \pm 0.01 \mathrm{~mm}$ thickness for optical measurements were prepared by cutting, grinding, and polishing with cerium oxide.

The density of the glasses was measured by the Archimedes method using toluene as the immersion liquid with an error of $\pm 0.7 \%$. The UV-vis-NIR absorption spectra were recorded with a double-beam spectrophotometer (Perkin-Elmer, Lambda 20) at the wavelength error of $\pm 0.1 \mathrm{~nm}$. Transmission electron microscopy (TEM) was done using a Jeol (model JEM 2010) operating at $200 \mathrm{kV}$. Crystallographic characterization of the bulk samples was done with X-ray diffractoneter (PANalyical X'pert PRO) operating at $40 \mathrm{kV}$ and $30 \mathrm{~mA}$ using Ni-filtered $\mathrm{Cu}$ $\mathrm{K} \alpha(\lambda=1.5406 \AA)$ radiation with the $\mathrm{X}^{\prime}$ celerator step size $0.05^{\circ}(2 \theta)$ and step time $0.5 \mathrm{~s}$ from 10 to $80^{\circ}$. Fluorescence spectra were measured, at the error of $\pm 0.2 \mathrm{~nm}$, with a fluorescence spectrophotometer (Spex, Fluorolog 2) using a $150 \mathrm{~W}$ Xenon lamp as the excitation source and a photomultiplier tube as a detector. All the measurements were carried out at room temperature.

\section{Results and discussion}

The composition and some of the physical properties of the nanocomposites are listed in Table 1. All the nanocomposites were obtained in the monolithic form. The density is found to linearly increase with increase in dopant concentration. They showed uniform intense coloration indicating their potential use as decorative items as well. The change in color of the nanocomposites is attributed to the different $\mathrm{Au}$ and $\mathrm{Ag}$ concentration ratios which lead to the shift of the SPR band frequency in the visible region.

Figure 1 shows the UV-Vis absorption spectra of base glass, pure $\mathrm{Au}$, pure $\mathrm{Ag}$, and a series of $\mathrm{Au}$ Ag alloy embedded nanocomposites (thickness $=2$ $\mathrm{mm}$ ) with varying Au concentration while keeping Ag concentration constant. The peaks at $681 \mathrm{~nm}$ and $554 \mathrm{~nm}$ belong to surface plasmon absorption of pure $0.3 \mathrm{wt} \% \mathrm{Au}$ (Fig. 1(g)) and $0.006 \mathrm{wt} \%$ Ag (Fig. 1(b)) doped nanocomposites, respectively.

According to the Mie theory the position of the SPR band maxima ( $\lambda_{\max }$ ) of spherical noble metal $\left(\mathrm{Au}^{0}\right.$ and $\left.\mathrm{Ag}^{0}\right) \mathrm{NPs}$ is sensitive to changes in refractive index (RI, $n)$ of the embedding medium as [26]

$$
\lambda_{\max }^{2}=(2 \pi c)^{2} m N e^{2}\left(\varepsilon_{\infty}+2 n^{2}\right) / \varepsilon_{0}
$$

where $c$ is the speed of light, $m$ is effective mass of conduction electrons, $N$ is the free electron concentration, $e$ is the electronic charge, $\varepsilon_{0}$ is the free space permeability, and $\varepsilon_{\infty}$ is the optical dielectric function of the metal. Sodalime silicate glasses 


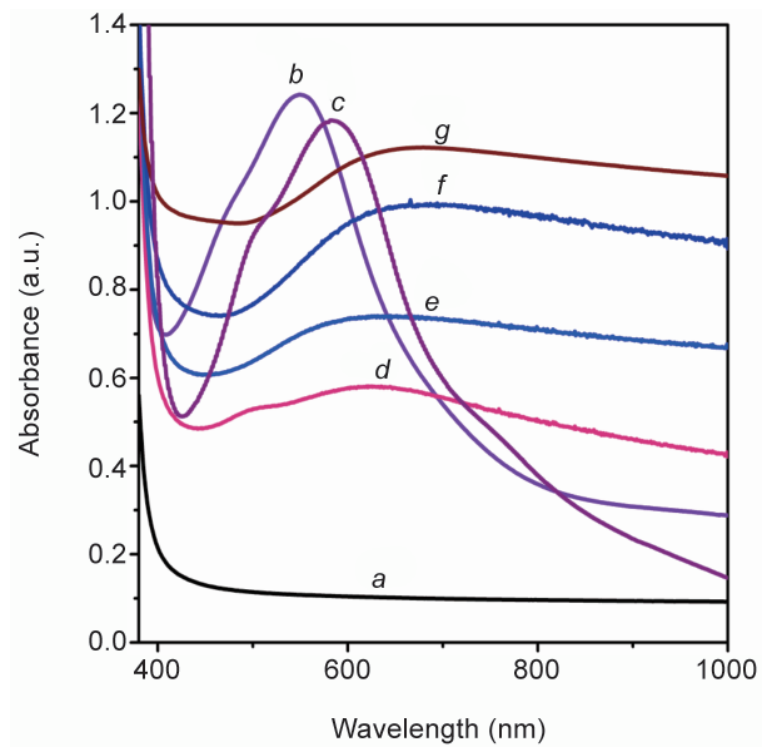

Figure 1 UV-vis spectra of the base glass, Ag, Au, and Au-Ag alloy embedded antimony glass nanocomposites showing the plasmonic band red shift with increasing Au/Ag ratio. (a) A1, (b) $A 2$, (c) $A 3$, (d) $A 4$, (e) $A 5$, (f) A6, and (g) A7 (thickness $=2 \mathrm{~mm}$, for composition see Table 1)

(n 1.5) features plasmon peak of $\mathrm{Au}^{0}$ and $\mathrm{Ag}^{0} \mathrm{NPs}$ at around 520 and $410 \mathrm{~nm}$, respectively [8]. It is known that higher $(n)$ of matrix shifts the SPR band towards longer wavelength. So, our $\mathrm{K}_{2} \mathrm{O}-\mathrm{B}_{2} \mathrm{O}_{3}-\mathrm{Sb}_{2} \mathrm{O}_{3}$ (KBS) antimony glass having high RI $(n=1.9477)$ significantly red-shifts the $\mathrm{Au}^{0}$ and $\mathrm{Ag}^{0}$-SPR peak to about 681 and $554 \mathrm{~nm}$, respectively.

The alloy formation is indicated from the fact that the optical absorption spectrum shows only one composition-sensitive plasmon band in between the absorption peaks of the two pure metal NPs and the SPR peak increases in a monotonic fashion (Table 1) [19, $27,28]$. The plasmon bands are slowly red-shifted from
Ag peak position $(554 \mathrm{~nm})$ towards $\mathrm{Au}$ peak position (681 nm) depending on increasing Au/ Ag ratio.

The TEM images of the nanocomposites (Figs. 2(a) -(c)) show the formation of core-shell geometries with sizes varying from $28-89 \mathrm{~nm}$. Generally, Au-Ag coreshell NPs in the form of $\mathrm{Au}_{\text {core }} @ \mathrm{Ag}_{\text {shell }}$ or $\mathrm{Ag}_{\text {core }} @ \mathrm{Au}_{\text {shell }}$ are synthesized by successive reduction of one metal ion over the core of the other. Their optical properties depend critically on the relative composition/ thickness of the core and the shell. If the shell is not very dense and thick, the surface plasmon of the core can effectively interact with the electromagnetic field so that the surface plasmon absorption of the core particles can be observed. In such cases, two distinct SPR peaks corresponding to pure $\mathrm{Ag}^{0}$ and $\mathrm{Au}^{0} \mathrm{NPs}$ are observed. In some cases of Au@Ag core-shell $\mathrm{NPs}$, where $\mathrm{Ag}^{0}$ shell is sufficiently thick, only the $\mathrm{Ag}^{0}$ SPR peak is observed demonstrating their relative composition/thickness dependent optical properties $[19,27,28]$. Also, the TEM images of bimetallic Ag@ Au core-shell NPs are known to display areas of contrasting density with the dark region attributable to gold and the light region attributable to silver [29].

In view of the above and on the standard reduction potential values $\left(\mathrm{Sb}^{5+} / \mathrm{Sb}^{3+}, E^{0}=0.6490\right.$ $\mathrm{V} ; \mathrm{Ag}^{+} / \mathrm{Ag}^{0}, E^{0}=0.7996 \mathrm{~V}$ and $\mathrm{Au}^{3+} / \mathrm{Au}^{0}, E^{0}=$ $1.4980 \mathrm{~V})$, [22] we suggest that the $\mathrm{Au}^{0} \mathrm{NPs}$ are first reduced leading to the formation of the core with predominant or pure Au concentration while the shell consists of $\mathrm{Au}-\mathrm{Ag}$ alloy. It is necessary to mention here that due to unavailability of redox data in glass melts at the melting temperature $\left(900^{\circ} \mathrm{C}\right)$, we consider here the standard reduction potential values

Table 1 Composition and some properties of Au-Ag alloy antimony glass nanocomposites

\begin{tabular}{|c|c|c|c|c|c|}
\hline Sample identity & Ag concentration ${ }^{a}(w t \%)$ & Au concentration ${ }^{\mathrm{a}}$ (wt\%) & Density $\left(\mathrm{g} / \mathrm{cm}^{3}\right)$ & SPR peak $(\mathrm{nm})$ & Color \\
\hline A1 & - & - & 4.550 & - & Yellow \\
\hline $\mathrm{A} 2$ & 0.006 & - & 4.556 & 554 & Deep-violet \\
\hline A3 & 0.006 & 0.003 & 4.564 & 588 & Violet \\
\hline A4 & 0.006 & 0.01 & 4.579 & 625 & Pink \\
\hline A5 & 0.006 & 0.03 & 4.585 & 638 & Light- blue \\
\hline A6 & 0.006 & 0.3 & 4.591 & 670 & Blue \\
\hline A7 & - & 0.3 & 4.587 & 681 & Brown \\
\hline
\end{tabular}

${ }^{a}$ Base glass (A1) composition (mol\%): $15 \mathrm{~K}_{2} \mathrm{O}-15 \mathrm{~B}_{2} \mathrm{O}_{3}-70 \mathrm{Sb}_{2} \mathrm{O}_{3}$. Ag and/or Au concentration(s) is(are) in excess. 
at room temperatures. The nanoparticle alloying can, in principle, result from an increase in the diffusion coefficient of the metals, because the melting point lowers as their size decreases [30]. The melting points of bulk Au and Ag are $1064.18{ }^{\circ} \mathrm{C}$ and $961.78{ }^{\circ} \mathrm{C}$, respectively [22]. Also, the atomic size of $\mathrm{Ag}$ (atomic radius $=144 \mathrm{pm}$ ) is same to that of $\mathrm{Au}$ (atomic radius $=144 \mathrm{pm}$ ), this results in an easy inter-diffusion between $\mathrm{Au}^{0}$ and $\mathrm{Ag}^{0}$ atoms.

The selected area electron diffractogram (SAED), Fig. 2(d), obtained for alloy encapsulated nanocomposites proves to be of little help in establishing the nature of alloy and core-shell morphology of the particles because their $d$-spacings are very close to one another. The particles display distinct ring patterns demonstrating their crystallinity. The diffraction pattern agrees well with the standard $d$-spacing values of both $\mathrm{Au}^{0}$ and $\mathrm{Ag}^{0}$. Unfortunately, the values for $\mathrm{Au}^{0}, \mathrm{Ag}^{0}$ and their alloy are within $\pm 1 \%$ of each other due to their similar atomic radii and chemical nature, and are hence indistinguishable.

Since $\mathrm{Au}^{0}$ and $\mathrm{Ag}^{0}$ have similar lattice constants (4.078 and $4.086 \AA$, respectively), routine X-ray diffraction also fails to distinguish the alloy compositions [31]. But the X-ray diffraction can be used to estimate the average crystallite sizes. Figure 3 compares the XRD patterns of the $\mathrm{Ag}^{0}$ and bimetallic $\mathrm{Au}^{0}-\mathrm{Ag}^{0}$ alloy containing nanocomposites with the base glass which has an amorphous nature. The nanocomposites A2-A6 show diffraction peaks of $\mathrm{Au}^{0}$ and $\mathrm{Ag}^{0}$ at $2 \theta=38.1144^{\circ}(d=2.36113 \AA)$

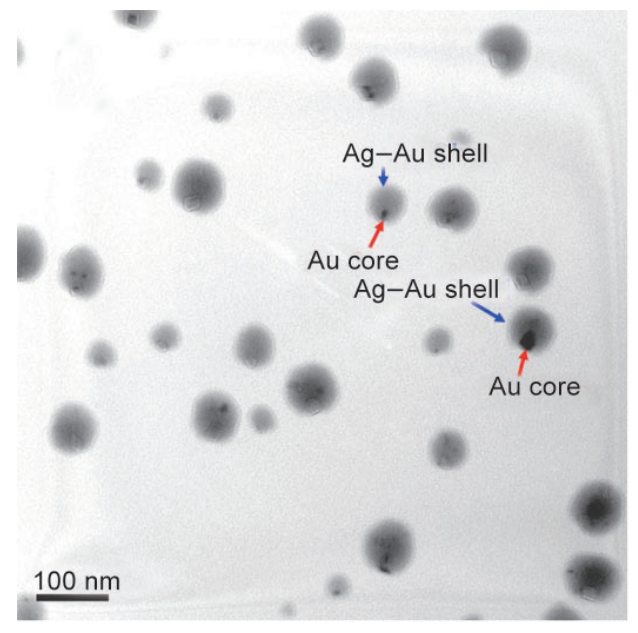

(a)

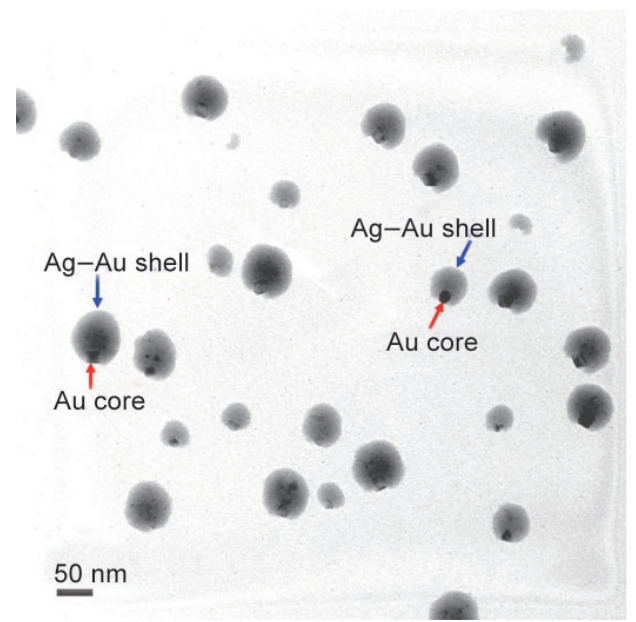

(c)

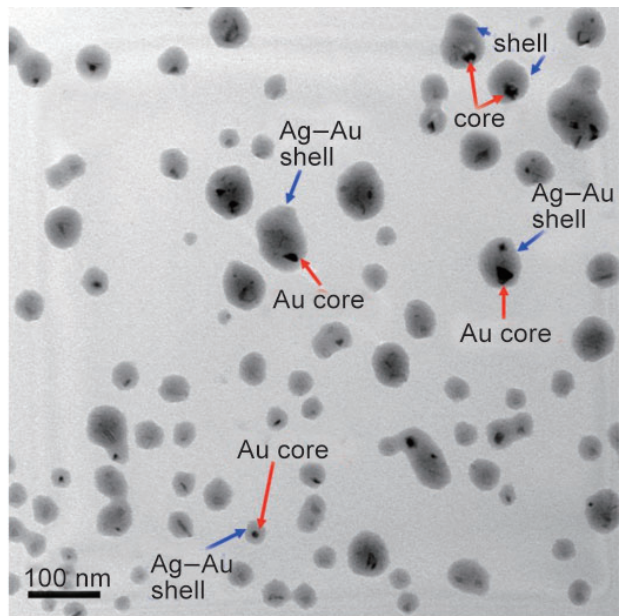

(b)

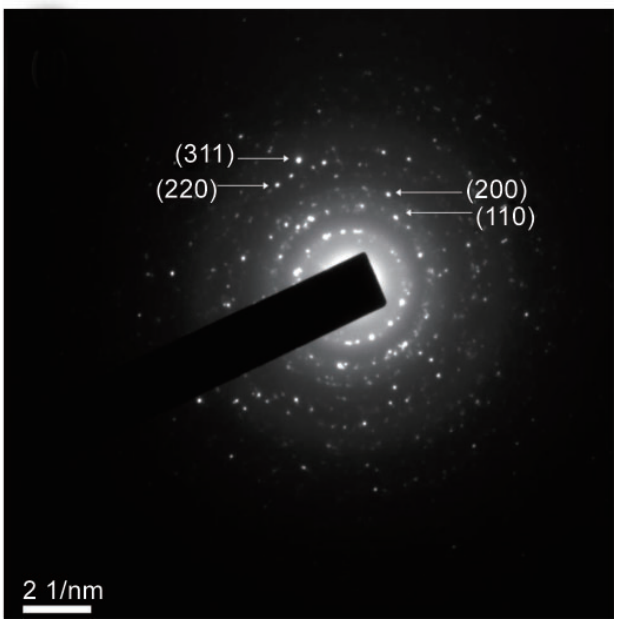

(d)

Figure 2 (a)-(c) TEM images of the Au-Ag alloy embedded antimony glass nanocompopsite A4 showing core-shell morphology, and corresponding (d) SAED image (for composition see Table 1) 


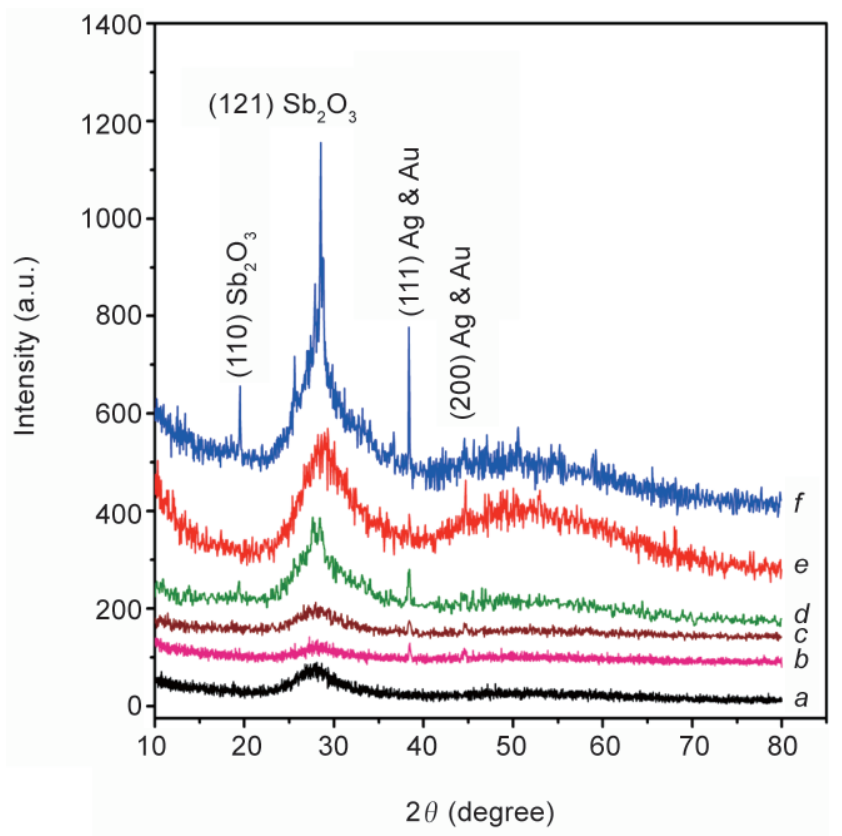

Figure 3 X-ray diffraction patterns of the base glass and Au-Ag alloy embedded antimony glass nanocomposites: (a) A1, (b) A2, (c) A3, (d) A4, (e) A5, and (f) A6 (for composition see Table 1)

and $44.760^{\circ}(d=2.0231 \AA)$ which corresponds to the (111) and (200) Bragg's reflections from the face centered cubic (fcc) structures of $\mathrm{Au}$ and Ag nanocrystals (JCPDS card file nos. 4-0784 and 4-0783, respectively). However, the XRD diffraction peaks are fairly weak because the concentration of the nano metal embedded within bulk amorphous dielectric (KBS glass) matrix is very low. The XRD spectrum manifests the reduction of $\mathrm{Ag}^{+}$to $\mathrm{Ag}^{0}$ metal and $\mathrm{Au}^{3+}$ to $\mathrm{Au}^{0}$ by the reducing glass matrix component $\mathrm{Sb}_{2} \mathrm{O}_{3}$ since no other external reducing agent is used. The peaks at $2 \theta=19.4042^{\circ}(d=4.57460 \AA)$ and $28.3919^{\circ}$ $(d=3.14361 \AA)$ can be indexed to (110) and (121) reflections from valentinite phase of $\mathrm{Sb}_{2} \mathrm{O}_{3}$ crystals (JCPDS card file no. 11-0689) manifesting partial crystallization of the $\mathrm{Sb}_{2} \mathrm{O}_{3}$-based glass matrix in presence of $\mathrm{Au}^{0}$ and $\mathrm{Ag}^{0} \mathrm{NPs}$ acting as heterogeneous nucleation sites [32]. The particle size estimated from the diffraction peaks using Scherrer's equation [33] are seen to linearly increase from 50 to $90 \mathrm{~nm}$ with increasing concentration of $\mathrm{Au}$.

The superiority and flexibility of the present versatile method is demonstrated by synthesizing RE (here $\mathrm{Sm}^{3+}$ ): $\mathrm{Au}^{0}-\mathrm{Ag}^{0}$ co-doped antimony-based nanocomposite by similar single-step route. The mechanism can be interpreted using reduction potential values $\left(\mathrm{Sm}^{3+} / \mathrm{Sm}^{0}, E^{0}=-2.304 \mathrm{~V}\right.$ and $\mathrm{Sb}^{5+} / \mathrm{Sb}^{3+}=0.649 \mathrm{~V}$ ) [22] which indicates that $\mathrm{Sb}^{3+}$ is unable to reduce $\mathrm{Sm}^{3+}$. The absorption spectra and the details of peak positions (energy levels) of 0.3 $w t \%$ (in excess) $\mathrm{Sm}_{2} \mathrm{O}_{3}$ doped base glass (A1) were described elsewhere [21]. The $\mathrm{Sm}^{3+}$ doped antimony glass exhibits an absorption band at $949 \mathrm{~nm}$. On excitation at $949 \mathrm{~nm}$ radiation, the processes of ground state absorption (GSA), followed by excited state absorption (ESA), energy transfer (ET), and cooperative energy transfer (CET) between two neighboring $\mathrm{Sm}^{3+}$ ions take place as:

$$
\begin{aligned}
& { }^{6} \mathrm{H}_{5 / 2} \rightarrow{ }^{6} \mathrm{~F}_{11 / 2} \text { [GSA] } \rightarrow{ }^{4} \mathrm{I}_{11 / 2} \text { [ESA] } \\
& \left({ }^{6} \mathrm{~F}_{11 / 2},{ }^{6} \mathrm{~F}_{11 / 2}\right) \rightarrow\left({ }^{4} \mathrm{I}_{11 / 2},{ }^{6} \mathrm{H}_{5 / 2}\right) \text { [ET] } \\
& \left({ }^{4} \mathrm{I}_{9 / 2},{ }^{6} \mathrm{~F}_{7 / 2}\right) \rightarrow\left({ }^{4} \mathrm{G}_{5 / 2},{ }^{6} \mathrm{~F}_{11 / 2}\right) \text { [CET] }
\end{aligned}
$$

This leads to the population of the metastable radiative storage level, ${ }^{4} \mathrm{G}_{5 / 2}$. Consequently, the $\mathrm{Sm}^{3+}$ doped glass shows upconverted emission bands observed at 566 (green, weak), 602 (orange, weak), 636 (red, very strong), and 649 (red, very weak) $\mathrm{nm}$ due to ${ }^{4} \mathrm{G}_{5 / 2} \rightarrow{ }^{6} \mathrm{H}_{5 / 2}(\Delta J=0$, zero-zero band, forbidden transition), ${ }^{4} \mathrm{G}_{5 / 2} \rightarrow{ }^{6} \mathrm{H}_{7 / 2}(\Delta J=1$, magnetic dipole transition), ${ }^{4} \mathrm{G}_{5 / 2} \rightarrow{ }^{6} \mathrm{H}_{9 / 2}(\Delta J=2$, electric dipole transition), and ${ }^{4} \mathrm{G}_{5 / 2} \rightarrow{ }^{6} \mathrm{H}_{11 / 2}(\Delta J=3$, forbidden transition), respectively [21]. These are shown in Fig. 4 and explained with the help of partial energy level diagram of $\mathrm{Sm}^{3+}$ ion in KBS glass as shown in Fig. 5.

Photoluminescence upconversion studies of the $\mathrm{Sm}^{3+}: \mathrm{Au}-\mathrm{Ag}$ co-doped nanocomposites carried out under the same excitation wavelength show that the electric dipole allowed ${ }^{4} \mathrm{G}_{5 / 2} \rightarrow{ }^{6} \mathrm{H}_{9 / 2}$ transitions undergoes $\sim 2$ folds intensity enhancement in presence of the core-shell Au-Ag NPs. It is to be noted here that different intermetallic:rare-earth ions co-embedded ( $\left.\mathrm{Au}-\mathrm{Ag}: \mathrm{Sm}^{3+}\right) \mathrm{KBS}$ glasses having concentrations (in wt\%) (a) $0.006 \mathrm{Ag}-0.003 \mathrm{Au}: 0.3$ $\mathrm{Sm}^{3+}$, (b) $0.006 \mathrm{Ag}-0.01 \mathrm{Au}: 0.3 \mathrm{Sm}^{3+}$, (c) $0.006 \mathrm{Ag}-0.03$ Au: $0.3 \mathrm{Sm}^{3+}$, and (d) $0.006 \mathrm{Ag}-0.3 \mathrm{Au}: 0.3 \mathrm{Sm}^{3+}$ have been examined for fluorescence enhancement. The maximum enhancement was found to be about 2 folds in the case of (b) $0.006 \mathrm{Ag}-0.01 \mathrm{Au}: 0.3 \mathrm{Sm}^{3+}$. For this reason, we have presented its photoluminescence upconversion spectrum in Fig. 4 (curve-c) for simplicity and clear visibility excluding others. Such 
enhancement of fluorescence is attributed to the local electric field enhancement (LFE, $E_{x}$ ) and energy transfer (ET) from $\mathrm{Au}-\mathrm{Ag}$ NPs to $\mathrm{Sm}^{3+}$ (as shown in Fig. 5). These hybrid nanocomposites appear to be potential candidates for display and laser devices. Inset of Fig. 4 shows the Au-Ag core-shell NPs enhanced $\mathrm{Sm}^{3+}$ photoluminescence red upconversion photograph of antimony glass nanocomposites excited at $949 \mathrm{~nm}$.

The metal nanostructures result in giant and highly spatially localized electric fields around $\mathrm{Sm}^{3+}$ ion [12-14]. This is because the surface plasmon waves (surface plasmon polaritons) generated by electronic oscillations (SPR) travel along the surface of the metal NPs, concentrate light in the subwavelength structures due to the difference in relative permittivity of the metal and the surrounding glass matrix $[15,16]$. Concentration of light and effect of metallic screening lead to amplification of the local electric field around the metal nanostructures (by "Lightning Rod Effect") with respect to the incident field [15]. Thus, the metal NPs provide a unique

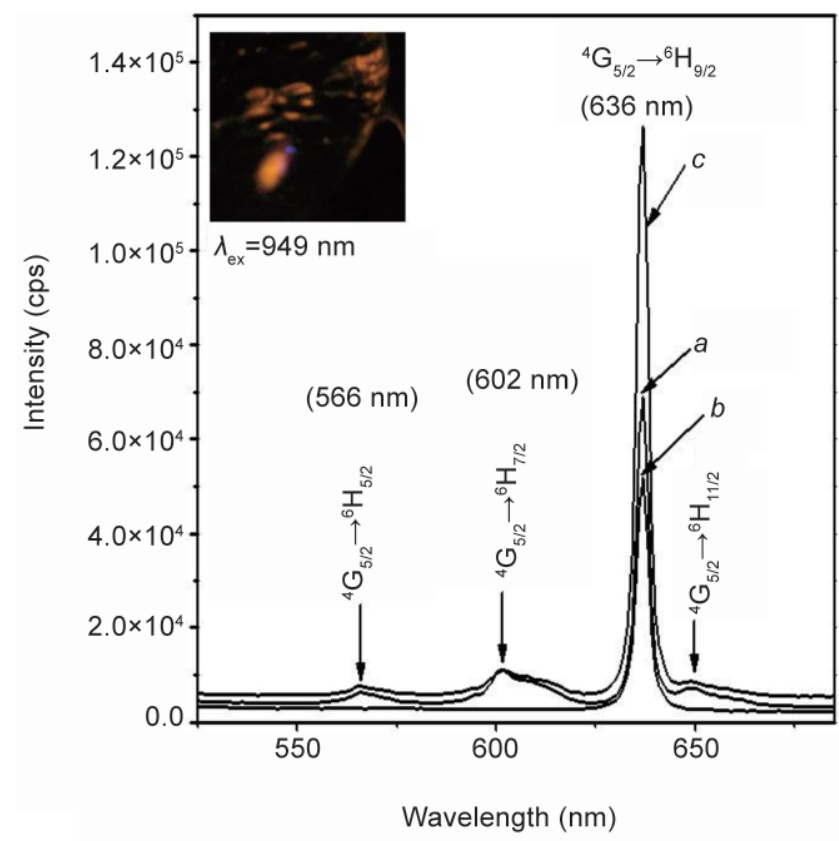

Figure 4 Upconversion spectra of (a) $\mathrm{A} 1$ with $0.3 \mathrm{wt} \% \mathrm{Sm}^{3+}$-doped, (b) $\mathrm{A} 4$, and (c) A1 with $0.3 \mathrm{wt} \% \mathrm{Sm}_{2} \mathrm{O}_{3}$ and, $0.006 \mathrm{wt} \% \mathrm{Ag}$ and $0.01 \mathrm{wt} \%$ Au co-doped, excited at $\lambda_{\mathrm{ex}}=949 \mathrm{~nm}$ (for composition see Table 1). The unit cps stands for photon counts per second. Inset shows the $\mathrm{Au}-\mathrm{Ag}$ core-shell nanoparticles enhanced $\mathrm{Sm}^{3+}$ photoluminescence red upconversion photograph of antimony glass nanocomposites excited at $\lambda_{\mathrm{ex}}=949 \mathrm{~nm}$ opportunity to modify the fluorescence due to changes in the rates of excitation and emission of RE ions. Within glass matrices, the influence of metallic particles on the absorption and emission rates of RE ions is primarily of electronic origin $[34,35]$. This can be envisaged as an additional interaction due to the high field gradients in the vicinity of metal NPs produced by plasmonic excitation of the particles at the Mie resonance frequency (SPR) [34, 35].

Although localized excitation and increased quantum yield near metal NPs are desired but practically both enhancing and quenching of RE ions or fluorophores (as the case may be) takes place near the metal particles [36, 37]. It has been well documented in literature that to achieve enhancement of fluorescence, the fluorophore molecule must be located at a distance of $50 \AA$ or more from the metal surface to avoid quenching at a distance shorter than this [35]. There are also zones near the surface where the enhancement effect is maximum because the local field decreases exponentially from the surface $[16,35]$. Infact, the interactions between RE

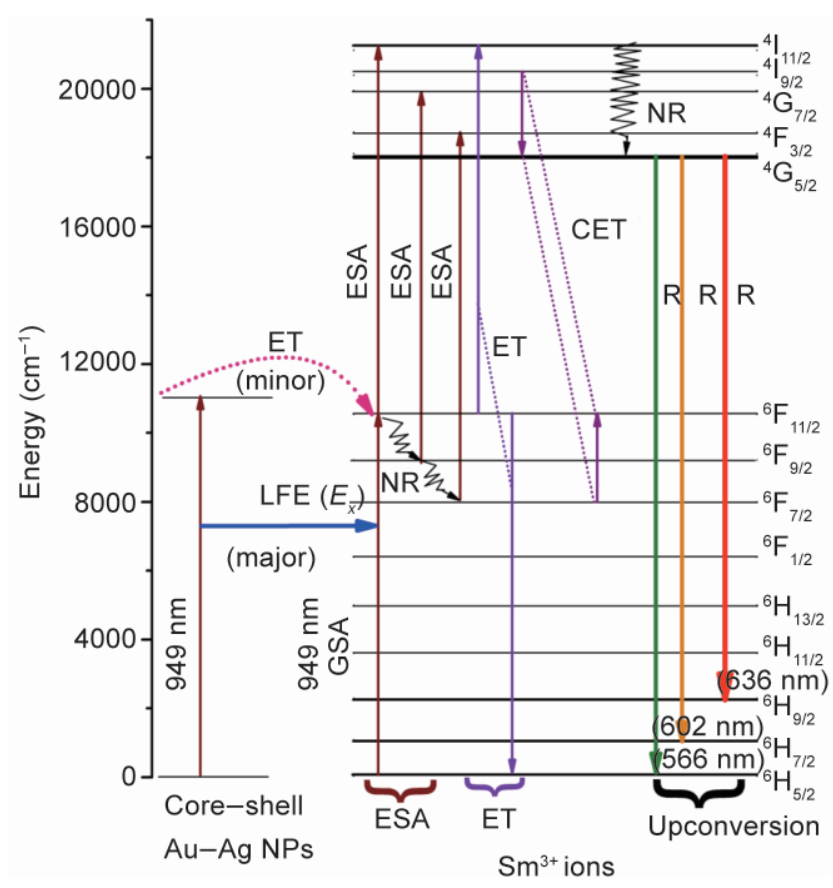

Figure 5 Partial energy level diagram of $\mathrm{Sm}^{3+}$ ion in $15 \mathrm{~K}_{2} \mathrm{O}-15 \mathrm{~B}_{2} \mathrm{O}_{3}$ $-70 \mathrm{Sb}_{2} \mathrm{O}_{3}(\mathrm{~mol} \%)$ glass showing upconversion fluorescence emissions at 566, 602 and $636 \mathrm{~nm}$ through GSA, ESA, ET, and CET between $\mathrm{Sm}^{3+}$ ions. LFE by SPR of core-shell $\mathrm{Au}^{\circ}-\mathrm{Ag}^{\circ} \mathrm{NPs}$ and ET from $\mathrm{Au}^{\circ}-$ $\mathrm{Ag}^{\circ} \mathrm{NPs}$ to $\mathrm{Sm}^{3+}$ ions in nanocomposites are also shown (R and NR represent the radiative and nonradiative transitions, respectively) 
ions and/or fluorophore molecules with metals is quite complex and depend on a variety of factors like metal type, fluorophore type, the sizes of novel metal NPs, distance between fluorophore and metal particle surface, and molecule dipole orientation versus particle surface, etc.[37-40]. For example, small sized metallic particles have larger field effects than continuous metallic surfaces [37]. However, it is very difficult to precisely predict the effect of each such parameter on the fluorescence properties of $\mathrm{Sm}^{3+}$ ions with KBS glasses doped with $\mathrm{Au}-\mathrm{Ag}$ alloy nanoclusters. The morphological variations (e.g., spherical, elliptical, rod-shaped, triangles, etc.) of the metal NPs play a crucial role in the nanometal enhanced fluorescence process. In this regard, anisotropic NPs with sharp edges are more potential candidates for nanometal enhanced fluorescence studies [14]. Electromagnetic excitations are known to induce surface charges. The local surface charge densities are severely increased and confined near the sharp edges of anisotropic nanostructures which act as light-harvesting nano optical antennas converting visible light into large localized electric field ("lightning-rod effect") [15]. Therefore, quasispherical Au-Ag nanostructures with sharp edges (see Fig. 2) near the $\mathrm{Sm}^{3+}$ ions not only increases the excitation rate of $\mathrm{Sm}^{3+}$ ions but the hypersensitive ${ }^{4} \mathrm{G}_{5 / 2} \rightarrow{ }^{6} \mathrm{H}_{9 / 2}$ transition also undergoes a forced electric dipole transition since the $\mathrm{Sm}^{3+}$ ions are present in the highly polarizable asymmetric geometric environment of KBS antimony glasses.

Another interesting observation is that under pump excitation at $949 \mathrm{~nm}$, the $\mathrm{Au}-\mathrm{Ag}$ co-doped nanocomposite also emits photons at $636 \mathrm{~nm}$ (energy $\sim 15,723 \mathrm{~cm}^{-1}$ ) due to the following reasons. Generally, the inherent large nonlinear optical response of a dielectric hosts (glass, polymers, etc.) may be enhanced by several folds by insertion of small metal clusters [41]. The molar polarizability (as calculated from Lorentz-Lorenz equation) and refractive index of KBS antimony glass of the present study are found to be $9.598 \AA^{3}$ and 1.947 respectively. These properties of antimony glass are very much higher compared to other normal glasses such as of silica glass (molar polarizability $=2.965 \AA^{3}$ and refractive index $=1.46$ ). It is well recognized that glasses of high polarizability are expected to have large nonlinear optical properties. Terashima et al. [23] have demonstrated that $\mathrm{Sb}_{2} \mathrm{O}_{3}$ glass possesses about 30 times higher nonlinear optical susceptibility than that of $\mathrm{SiO}_{2}$ glass.

Thus, when excited by NIR light, $\mathrm{Au}-\mathrm{Ag}$ co-doped antimony nanocomposites are found to emit visible photons due to their enhanced large nonlinear optical properties. Formation of near(quasi)-spherical core -shell $\mathrm{Au}-\mathrm{Ag}$ alloy nanostructures inside the hard, stable, and flexible inert glass matrix with inherent nonlinear optical properties suggest the potential use of these nanocomposites in nonlinear optics-based appliances. The additional electric field induced by large nonlinear optical glass host may also make some contribution to the allowed electric dipole ${ }^{4} G_{5 / 2}$ $\rightarrow{ }^{6} \mathrm{H}_{9 / 2}$ transition which results in red fluorescence enhancement.

\section{Conclusions}

A new single-step methodology (selective thermochemical reduction) has been developed to generate a new series of $\mathrm{Au}-\mathrm{Ag}$ nanoparticles with core-shell morphology embedded bulk antimony glass monolithic nanocomposites without addition of any external reducing agent. The formation of an alloy shell was monitored by the UV-vis absorption spectroscopy which shows that the plasmon bands are slowly red-shifted from Ag peak position (554 $\mathrm{nm})$ towards $\mathrm{Au}$ peak position $(681 \mathrm{~nm})$ depending on increasing $\mathrm{Au} / \mathrm{Ag}$ ratio. The TEM images confirm the formation of the resultant core-shell particles. The XRD patterns show the presence of (111) and (200) crystallographic planes of fcc $\mathrm{Au}-\mathrm{Ag}$ nano particles. Formation of core-shell $\mathrm{Au}-\mathrm{Ag}$ nanostructures in the hard, stable, and flexible inert glass matrix with inherent nonlinear optical properties suggest the potential use of these nanocomposites in nonlinear optical related applications as well. The superiority of the present versatile method has also been demonstrated by synthesizing $\mathrm{Sm}^{3+}: \mathrm{Au}^{0}-\mathrm{Ag}^{0} \mathrm{co}-$ doped antimony-based nanocomposite by similar single-step route and mechanism has also been discussed using reduction potential values. The photoluminescence upconversion studies of this 
co-embedded nanocomposite at $949 \mathrm{~nm}$ excitation shows that the $636 \mathrm{~nm}$ red emission of $\mathrm{Sm}^{3+}$ ions arising due to ${ }^{4} \mathrm{G}_{5 / 2} \rightarrow{ }^{6} \mathrm{H}_{9 / 2}$ transition which remarkably undergoes about 2 folds enhancement of luminescence intensity in presence of such coreshell particles. Such enhancement of fluorescence is attributed to the local field enhancement and energy transfer from $\mathrm{Au}-\mathrm{Ag}$ nanoparticles to $\mathrm{Sm}^{3+}$. This codoped nanocomposite would find application in display devices and laser sources. We believe that this would open new vistas in the area of any reducing dielectric (e.g., glasses) containing nanocomposites.

\section{Acknowledgements}

One of the authors (T. S.) gratefully acknowledges the financial support of the Council of Scientific and Industrial Research (CSIR), New Delhi in the form of NET-SRF under sanction number 31/015(0060)/2007-EMR-1. They gratefully thank Dr. H. S. Maiti, Director of this institute for his kind permission to publish this work. The technical support provided by the infrastructural facility of this institute (X-ray Division) and National TEM Facility Center, IIT, Kharagpur are also thankfully acknowledged.

Electronic Supplementary Materials: Supplementary materials give the detailed applicability of the present single-step method to other hybrid nanocomposites and their photonic applications. It is available in the online version of this article at http://dx.doi. org/10.1007/s12274-009-9061-4 and is accessible free of charge.

\section{References}

[1] Hu, M. -S.; Chen, H. -L.; Shen, C. -H.; Hong, L. -S.; Huang, B. -R.; Chen, K. -H.; Chen, L. -C. Photosensitive gold-nanoparticle-embedded dielectric nanowires. Nat. Mater. 2006, 5, 102-106.

[2] Liu, J. F.; Chen, W.; Liu, X. M.; Zhou, K. B.; Li, Y. D. Au/LaVO Nanocomposite: Preparation, characterization, and catalytic activity for CO oxidation. Nano Res. 2008, 1, 46-55.

[3] De, G.; Rao, C. N. R. Two-dimensional Au and Au$\mathrm{Cu}$ alloy nanocrystals with orientation in (111) plane embedded in glassy silica Films. J. Phys. Chem. B 2003,
107, 13597-13600.

[4] Armelao, L.; Barreca, D.; Bottaro, G.; Mattei, G.; Sada, C.; Tondello, E. Copper-silica nanocomposites tailored by the sol-gel route. Chem. Mater. 2005, 17, 1450-1456.

[5] Speranza, G.; Minati, L.; Chiasera, A.; Ferrari, M.; Righini, G. C.; Ischia, G. Quantum confinement and matrix effects in silver-exchanged soda lime glasses J. Phys. Chem. C 2009, 113, 4445-4450.

[6] Gonella, F.; Cattaruzza, E.; Battaglin, G.; D'Acaptio, F.; Sada, C.; Mazzoldi, P.; Maurizio, C.; Mattei, G.; Martorana, A.; Longo, A.; Zontone, E. Double implantation in silica glass for metal cluster composite formation: A study by synchrotron radiation techniques. J. Non-Cryst. Solids 2001, 280, 241-248.

[7] Zhang, J.; Dong, W.; Sheng, J. W.; Zheng, J. W.; Li, J.; Qiao, L.; Jiang, L. Q. Silver nanoclusters formation in ionexchanged glasses by thermal annealing, UV-laser and X-ray irradiation. J. Cryst. Growth 2008, 310, 234-239.

[8] Gonella, F.; Mazzoldi, P. Metal nanocluster composite glasses. In Handbook of Nanostructured Materials and Nanotechnology; Nalwa, H. S., Eds. j. Academic Press: San Diego, 2000 Vol.4, p.81.

[9] Selvan, S. T.; Hayakawa, T.; Nogami, M.; Kobayashi, Y.; Liz-Marzán, L. M.; Hamanaka, Y.; Nakamura, A. Sol-gel derived gold nanoclusters in silica glass possessing large optical nonlinearities. J. Phys. Chem. B 2002, 106, 10157 -10162 .

[10] Hofmeister, H.; Drost, W. -G.; Berger A. Oriented prolate silver particles in glass-characteristics of novel dichroic polarizers. Nanostruct. Mater. 1999, 12, 207-210.

[11] Grabert, H.; Devoret, M. Single-Charge Tunneling; Plenum: New York, 1992.

[12] Kassab, L. R. P.; de Araújo, C. B.; Kobayashi, R. A.; de A Pinto, R. D.; da Silva, D. M. Influence of silver nanoparticles in the luminescence efficiency of $\mathrm{Pr}^{3+}$-doped tellurite glasses. J. Appl. Phys. 2007, 102, 103515 (1-4).

[13] Kassab, L. R. P.; Bomfim, F. A.; Martinelli, J. R.; Wetter, N. U.; Neto J. J.; de Araújo, C. B. Energy transfer and frequency upconversion in $\mathrm{Yb}^{3+}-\mathrm{Er}^{3+}$-doped $\mathrm{PbO}-\mathrm{GeO}_{2}$ glass containing silver nanoparticles. Appl. Phys. B 2009, 94, 239-242.

[14] Pompa, P. P.; Martiradonna, L.; Della Torre, A.; Della Sala, F.; Manna, L.; De Vittorio, M..; Calabi, F.; Cingolani, R.; Rinaldi, R. Metal-enhanced fluorescence of colloidal nanocrystals with nanoscale control. Nat. Nanotechnol. 2006, 1, 126-130. 
[15] Le, F.; Brandl, D. W.; Urzhumov, Y. A.; Wang, H.; Kundu, J.; Halas, N. J.; Aizpurua, J.; Nordlander, P. Metallic Nanoparticle Arrays: A common substrate for both surfaceenhanced Raman scattering and surface-enhanced infrared absorption. ACS Nano 2008, 2, 707-718.

[16] Barnes, W. L.; Dereux, A.; Ebbesen, T. W. Surface plasmon subwavelength optics. Nature 2003, 424, 824-830.

[17] Mattei, G.; de Julin Fernndez, C. D.; Mazzoldi, P.; Sada, C.; De, G.; Battaglin, G.; Sangregorio, C.; Gatteschi, D. Synthesis, structure, and magnetic properties of $\mathrm{Co}, \mathrm{Ni}$, and $\mathrm{Co}-\mathrm{Ni}$ alloy nanocluster-doped $\mathrm{SiO}_{2}$ films by sol-gel processing. Chem. Mater. 2002, 14, 3440-3447.

[18] Hosteler, M. J.; Zhong, C. -J.; Yen, B. K. H.; Anderegg, J.; Gross, S. M.; Evans, N. D.; Porter, M.; Murrary, R. W. Stable, monolayer-protected metal alloy clusters. J. Am. Chem. Soc. 1998, 120, 9396-9399.

[19] Ferrando, R.; Jellinek, J.; Johnston, R. L. Nanoalloys: From theory to applications of alloy clusters and nanoparticles. Chem. Rev. 2008, 108, 845-910.

[20] Mizukoshi, Y.; Fujimoto, T.; Nagata, Y.; Oshima, R.; Maeda, Y. Characterization and catalytic activity of core -shell structured gold/palladium bimetallic nanoparticles synthesized by the sonochemical method. J. Phys. Chem. B 2000, 104, 6028-6032.

[21] Som, T.; Karmakar, B. Infrared-to-red upconversion luminescence in samarium-doped antimony glasses. J. Lumin. 2008, 128, 1989-1996.

[22] Lide, D. R., CRC Handbook of Chemistry and Physics, 75th edn; CRC Press: Boca Raton, 1975; pp.8-21-34.

[23] Terashima, K.; Hashimoto, T.; Uchino, T.; Kim, S. -H.; Yoko, T. Structure and nonlinear optical properties of $\mathrm{Sb}_{2} \mathrm{O}_{3}-\mathrm{B}_{2} \mathrm{O}_{3}$ binary glasses. J. Ceram. Soc. Jpn. 1996, 104, 1008-1014.

[24] Nalin, M.; Messaddeq, Y.; Ribeiro, S. J. L.; Poulain, M.; Briois, V.; Brunlkaus, G.; Rosenhahn, C.; Mosel, B. D.; Eckert, $\mathrm{H}$. Structural organization and thermal properties of the $\mathrm{Sb}_{2} \mathrm{O}_{3}-\mathrm{SbPO}_{4}$ glass system. J. Mater. Chem. 2004, 14, 3398-3405.

[25] Vogel, W. Glass Chemistry; Springer-verlag: Berlin,1992.

[26] Persans, P. D.; Stokes, K. L. Embedded nanocrystal spectroscopy: Semiconductor and metal particles in inulators. In Handbook of Nanophase Materials; Golstein, A. N., Ed.; Marcel Dekker: New York, 1971; pp. 271-316.

[27] Peng, Z. Q.; Spliethoff, B.; Tesche, B.; Walther, T.; Kleinermanns, K. Laser-assisted synthesis of Au-Ag alloy nanoparticles in solution. J. Phys. Chem. B 2006, 110,
2549-2554.

[28] Chen, H. M.; Liu, R. S.; Jang, L. -Y.; Lee, J. -F.; Hu, S. F. Characterization of core-shell type and alloy $\mathrm{Ag} / \mathrm{Au}$ bimetallic clusters by using extended X-ray absorption fine structure spectroscopy. Chem. Phys. Lett. 2006, 421, 118-123.

[29] Srnova-Sloufova, I.; Lednicky, F.; Gemperle, A; Gemperlova, J. Core-shell (Ag)Au bimetallic nanoparticles: Analysis of transmission electron microscopy images. Langmuir 2000; 16, 9928-9935.

[30] Moskovits, M.; Srnova-Sloufova, I.; Vlekova, B. Bimetallic Ag-Au nanoparticles: Extracting meaningful optical constants from the surface-plasmon extinction spectrum. J. Chem. Phys. 2002, 116, 10435-10446.

[31] Papavassiliou, G. C. Surface plasmons in small Au-Ag alloy particles. J. Phys. F: Metal Phys. 1976, 6, L 103-106.

[32] Beall, G. H.; Duke, D. A. Glass ceramic technology. In Glass: Science and Technology; Uhlman, D. R.; Kreidl, N. J., Eds.; Academic Press: San Diego, 1983; vol 1.

[33] Cullity, B. D. Elements of X-Ray Diffraction; AddisonWesley Publishing Co: California, 1978.

[34] Hayakawa, T; Selvan, S. T.; Nogami, M. Field enhancement effect of small Ag particles on the fluorescence from $\mathrm{Eu}^{3+}$-doped $\mathrm{SiO}_{2}$ glass. Appl. Phys. Lett. 1999, 74, 1513-1515.

[35] Geddes, C. D.; Gryczynski, I.; Malicka, J.; Gryczynski, Z.; Lakowicz J. R. Metal-enhanced fluorescence: Potential applications in HTS. Comb. Chem. High Through. Screen. 2003, 6, 109-117.

[36] Zhu, J. SPR induced quenching of the ${ }^{5} D_{1} \rightarrow{ }^{7} F_{1}$ emission of $\mathrm{Eu}^{3+}$ doped gold colloids. Phys. Lett. A 2005, 341, 212 -215 .

[37] Matveeva, E. G.; Shtoyko, T.; Gryczynski, I.; Akopova, I.; Gryczynski, Z. Fluorescence quenching/enhancement surface assays: Signal manipulation using silver-coated gold nanoparticles. Chem. Phys. Lett. 2008, 454, 85-90.

[38] Stranik, O.; McEvoy, H. M.; McDonagh, C.; MacCraith, B. D. Plasmonic enhancement of fluorescence for sensor applications. Sens. Actuat. B 2005, 107, 148-153.

[39] Barnes, W. L. Fluorescence near interfaces: The role of photonic mode density. J. Mod. Opt. 1998, 45, 661-669.

[40] Enderlein, J. Single-molecule fluorescence near a metal layer. Chem. Phys. 247, 1, 1-9.

[41] Liao, H. B.; Wen, W. J.; Wong, G. K. L. Photoluminescence from Au nanoparticles embedded in Au: Oxide composite films. J. Opt. Soc. Am. B 2006, 23, 2518-2521. 